\title{
A Dilated Odontoma in the Second Molar Region of the Mandible
}

\author{
Yumiko Matsusue, Kazuhiko Yamamoto*, Kotaro Inagake and Tadaaki Kirita
}

Department of Oral and Maxillofacial Surgery, Nara Medical University, Kashihara, Nara 634-8522, Japan

\begin{abstract}
A case of dilated odontoma in the second molar region of the mandible was reported. The patient was a 14-year-old female. Panoramic X-ray and CT examination revealed an oval ring-shaped radiopaque lesion accompanying a radiolucent area in the center at the left second molar region of the mandible. The left second molar and all third molars were not found. The lesion was diagnosed as odontoma and extirpated under general anesthesia. The lesion was a spherical mass of $12 \times 9 \mathrm{~mm}$. Histologically, the mass was composed of dentin arranged in an oval ring shape with dentinal tubules. Inside the dentin, immature enamel was present. The central area of the mass was filled with fibrous tissue with a small nest of bone and cementum. Bone tissue was also observed in contact with the immature enamel layer. These morphological and histological features are compatible with those of a dilated odontoma.
\end{abstract}

Keywords: Dilated odontoma, Dens invaginatus, Molar, Mandible.

\section{INTRODUCTION}

Dens invaginatus (dens in dente, dilated odontoma) is a developmental tooth anomaly showing a broad spectrum of morphological variations, resulting from infolding of the enamel organ into the dental papilla before the mineralization phase [1-4]. The incidence of dens invaginatus is reported to range from $0.25 \%$ to $10 \%$ [1-3]. The most frequently affected tooth is the maxillary lateral incisors [5-7], followed by maxillary central incisors, premolars, canines and molars [1,2]. However, dens invaginatus is rarely found in mandibular teeth, especially molar teeth, although a few reports have shown the involvement of premolars [8-12].

Invagination ranges from slight pitting to an anomaly occupying most of the crown and root. Oehlers [13] classified dens invaginatus into 3 categories according to the depth of invagination. Type I: a minor form in which the enamellined invagination ends as a blind sac within the crown, not extending beyond the enamel-cemental junction. Type II: the enamel-lined invagination extends apically beyond the enamel-cemental junction, but remains within the root. Type III: the enamel-lined invagination extends apically beyond the enamel-cemental junction and perforates the surface of the root to create a second apical foramen.

A dens invaginatus also has a variant showing dilatation of the crown and/or root of the affected tooth. The most severe form of the dilated type of dens invaginatus is called a dilated odontoma, although it is not clearly defined as an independent entity in the current classification of odontogenic tumor. A dilated odontoma shows a completely inverted hard tissue structure due to severe invagination, often accompanied with central soft tissue and/or hard tissue.

*Address correspondence to this author at the Department of Oral and Maxillofacial Surgery, Nara Medical University, 840 Shijo-cho, Kashihara, Nara 634-8522, Japan; Tel/Fax: +81-744-29-8875;

E-mail: kazuyama@naramed-u.ac.jp

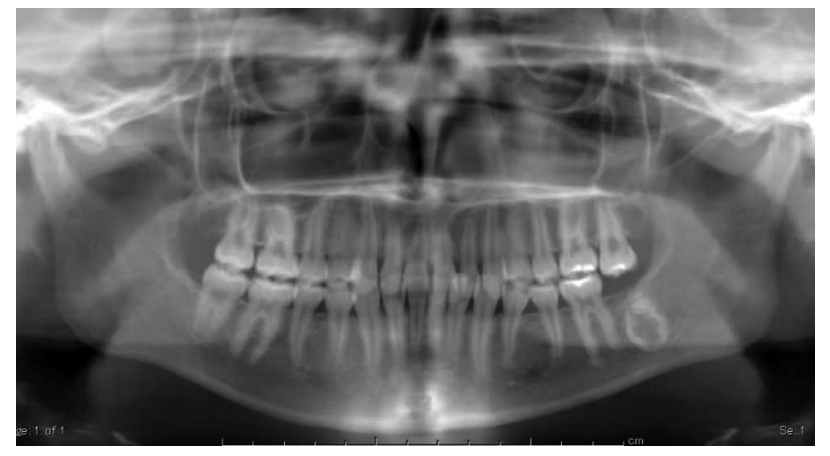

Fig. (1). Panoramic X-ray findings at the first visit An oval ring-shaped radiopaque lesion was observed in the left second molar region of the mandible.

A dilated odontoma in the molar region of the mandible is rare and only a few cases have been reported in the recent literature [14-16]. In this report, we present an extremely rare case of dilated odontoma arising in the second molar region of the mandible in a 14-year-old female.

\section{CASE REPORT}

A 14-year-old female patient was referred to our department for evaluation of the unerupted left second molar tooth of the mandible. She was well built and healthy without any medical complications. Her face was symmetric and no swelling of the cervical lymph nodes or hypoesthesia of the left lower lip was observed. Intraorally, the dentition of the permanent teeth was completed but the left second molar of the mandible was missing. The region was covered with healthy mucous membrane without a swelling or any bone eminence. Panoramic X-ray examination revealed an oval radiopaque lesion in the left second molar region of the mandible (Fig. 1). A radiolucent area was found within the lesion. The left second molar and all of the third molars were not found. CT examination also showed an oval ring-shaped 

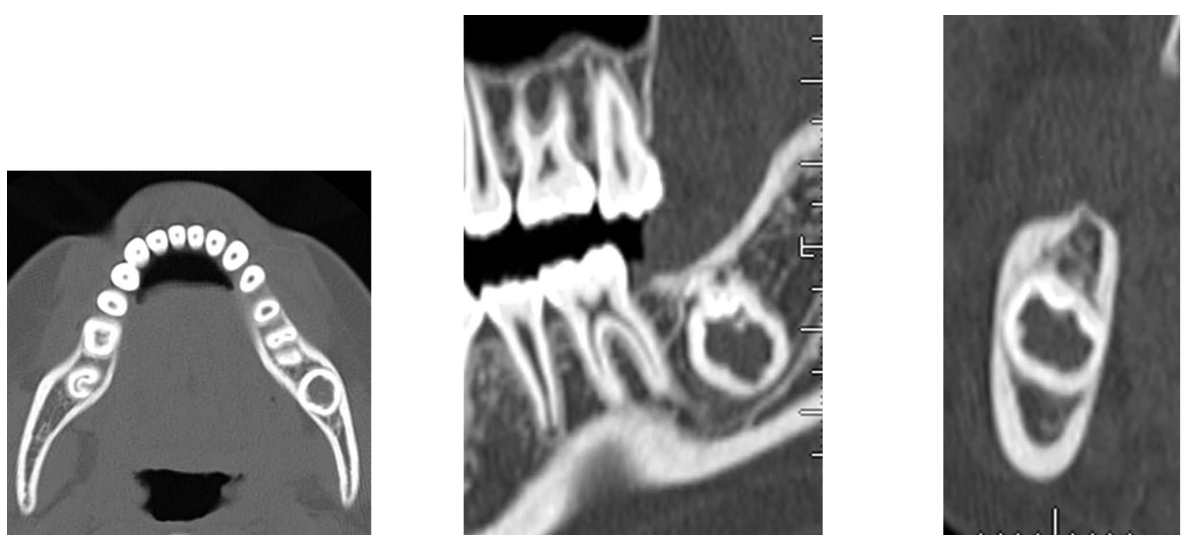

Fig. (2). CT findings at the first visit

a: Axial view

b: $\quad$ Panoramic view

c: $\quad$ Coronal view

An oval ring-shaped radiopaque lesion accompanying a radiolucent area in the center was observed.
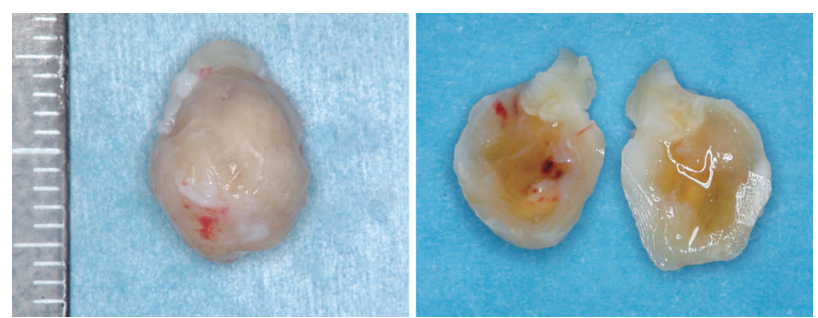

Fig. (3). Extirpated lesion

a: Whole view of the extirpated lesion

The extirpated lesion was a spherical hard mass of $12 \times 9 \mathrm{~mm}$ partly covered with thin soft tissue.

b:

Sliced surface of the lesion

The sliced surface showed hard tissue arranged in oval ring shape with soft tissue inside.

radiopaque lesion accompanying the radiolucent area in the center (Fig. 2a, b, c). The lesion was not related to the first molar. Bucco-lingual expansion of the mandible was not evident. Clinical diagnosis was odontoma in the left second molar region of the mandible.

She was admitted to our hospital and the lesion was extirpated under general anesthesia. After reflection of the mucoperiosteal flap, the lesion was identified by removing the buccal cortical bone and was easily extirpated en bloc. The wound was completely closed. The extirpated lesion was a spherical mass of $12 \times 9 \mathrm{~mm}$ covered with thin soft tissue (Fig. 3a). Morphological features of the crown or the root of the molar tooth were not evident. The sliced surface showed hard tissue arranged in an oval ring shape with soft tissue inside (Fig. 3b). Soft X-ray examination revealed that the hard tissue showed radiopacity similar to that of dentin, and the inner part was lined with a thin layer of high radiopacity like enamel (Fig. 4). The central area of the mass showed the radiolucency of soft tissue.

Macroscopic view of the histological specimen showed that the hard tissues were arranged in an oval ring shape and the inner portion was mainly filled with soft tissue (Fig. 5). Microscopically, the outer hard tissue was composed of dentin with dentinal tubules (Fig. 6a). Inside the dentin, a thin layer of immature enamel was observed showing a clear

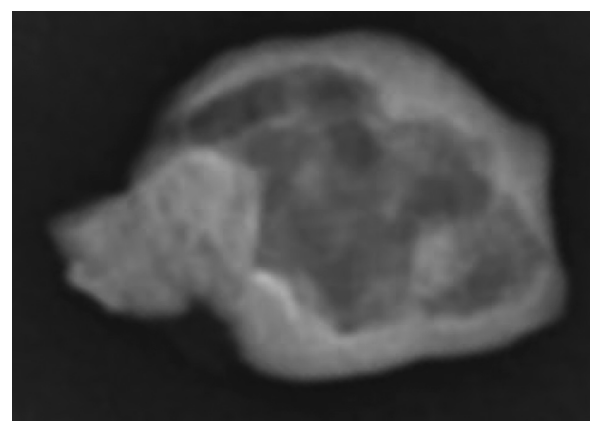

Fig. (4). Soft X-ray findings of the extirpated lesion

The outer hard tissue showed radiopacity similar to that of dentin. The inner part was lined with a thin layer of high radiopacity, like enamel. The central area of the mass showed the radiolucency of soft tissue.

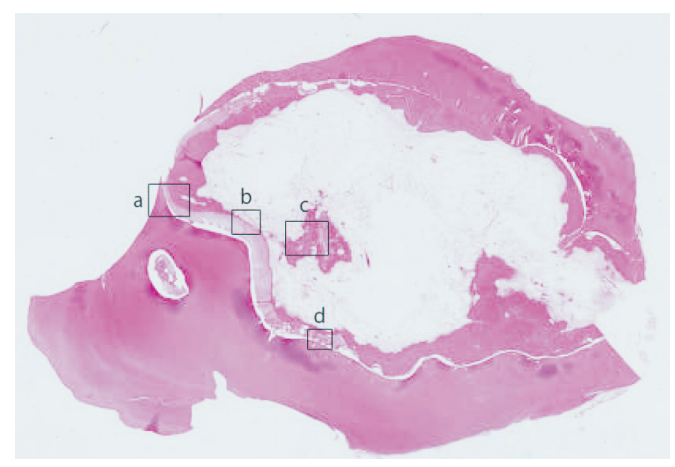

Fig. (5). Macroscopic histological view of the lesion Squares labeled 'a' 'b', 'c', 'd' correspond to the area shown in Fig. 6 a, b, c, d.

The hard tissues were arranged in an oval ring shape and the inner portion was mainly filled with soft tissue. Morphological features of the crown and root of the molar were not evident (H\&E, original magnification $\mathrm{x} 1$ ).

enamel rod structure (Fig. 6b). The central area of the mass was mostly filled with fibrous tissue with a small nest of bone and cementum (Fig. 6c). Bone tissue was also observed in contact with the immature enamel layer. In some areas, the border between the immature enamel and bone tissue was 


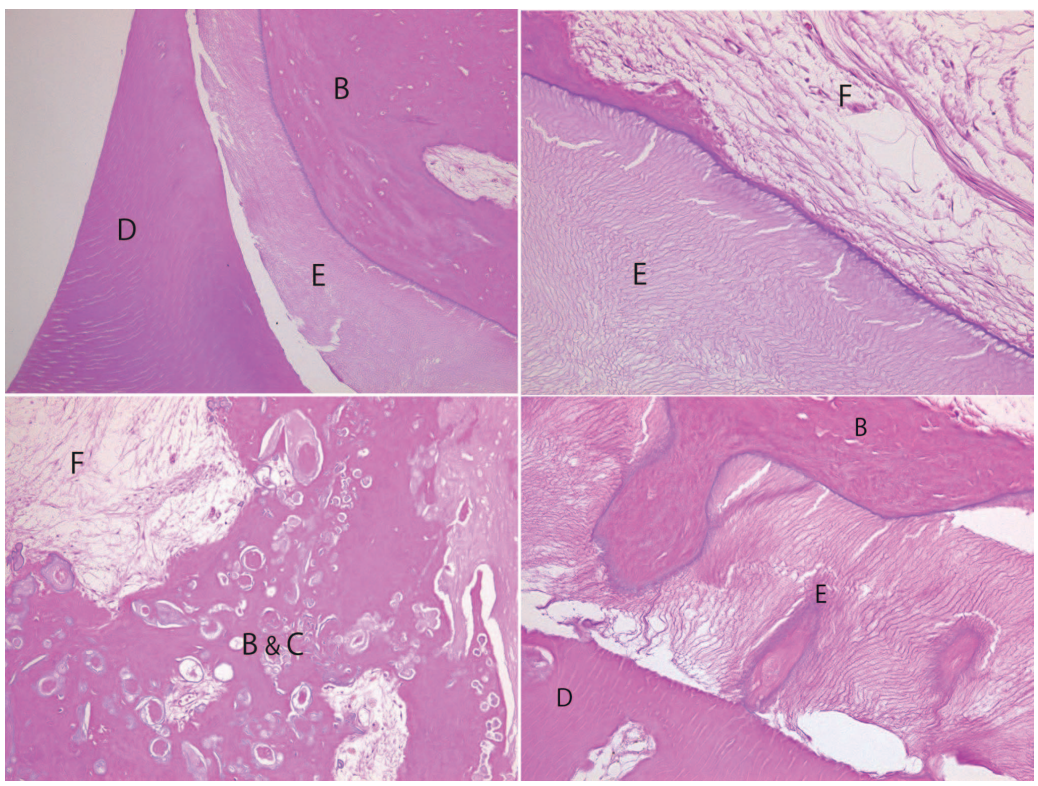

Fig. (6). Microscopic histological findings of the lesion.

D: Dentin, E: Enamel, B: Bone, F: Fibrous tissue, C: Cementum

a: $\quad$ Outer hard tissue was composed of dentin with dentinal tubules (H\&E, original magnification x 100).

b: $\quad$ A thin layer of immature enamel showing a clear enamel rod was observed inside the dentin (H\&E, original magnification $\mathrm{x} 150)$.

c: $\quad$ The central area of the mass was mostly filled with fibrous tissue with a small nest of bone and cementum (H\&E, original magnification $\mathrm{x} 100)$.

d: $\quad$ Bone tissue was also observed in contact with the immature enamel layer. In some areas, the border between immature enamel and bone tissue was irregular (H\&E, original magnification x200).

irregular (Fig. 6d). Pulp tissue was not observed in the specimen. These morphological and histological features are compatible with those of a dilated odontoma, in which histological arrangement of hard tissue structure is completely inverted from that of a normal tooth.

The postoperative course was uneventful. Six months after surgery, wound healing was good without any symptoms such as hypoesthesia of the left lower lip. Panorama X-ray examination also showed new bone synthesis in the left second molar region.

\section{DISCUSSION}

A dilated odontoma is a developmental dental anomaly presenting as a dilatation of the crown and root as the result of a deep, enamel-lined invagination and is considered a severe variant of dens invaginatus. The etiology and genesis of a dilated odontoma are not known, although several theories have been proposed, such as ingrowth of the enamel organ into the dental papilla, retardation of a focal group of cells, and external force by an adjacent tooth germ, trauma and infection [1]. A dens invaginatus occurs bilaterally in the premolar region [10-12], at high incidence in the parents and/or siblings of the patients [17], and with other dental abnormalities such as a microdontia, a macrodontia or a pumpkin-like shape with reduced ratio of the crown and root $[3,4,18-22]$, therefore, genetic factors are suggested as part of the cause.

A dilated odontoma developing in the molar region of the mandible is rare, although several cases might have been reported as a complex or compound odontoma. A few cases reported in the recent literature [14-16] were mostly observed in the third molar region of the mandible. The present case, developing in the second molar region of the mandible without a normally formed second molar tooth in the region, is considered extremely rare. A relatively simple form of an oval shape without morphological characteristics of a crown or root suggests that the invagination occurred in the very early stage of morphodifferentiation, accompanying other abnormalities of tooth development.

There are other types of examples possibly categorized as a dilated odontoma in the recent literature [4, 23, 24]. De Crincoli et al. [4] reported a case in the second molar region of the maxilla, showing a pumpkin-like morphology and a Cshaped pulp cavity. Continuity of enamel invaginated with that of the crown and pulp horn was clearly shown. Joubert et al. [23] reported a dilated odontoma in the third molar of the mandible. In this case, the bizarre malformation in the crown and upper half of the root showed the characteristics of a complex odontoma and the lower half of the root was almost normally formed. This is an example of a dilated odontoma categorized between dens invaginatus and complex odontoma. Stavrou et al. [24] reported a dilated odontoma in the root of the third molar of the maxilla. In this type, proliferation and ingrowth of Hertwig's epithelial root sheet into dental papilla occurred at the late stage of tooth development; therefore, the crown of the affected tooth was almost normally formed with marked dilatation of the root.

Tooth anomaly is observed in the dilated odontoma, not only in morphological and histological structures, but also in the mineral content of the hard tissue. Recent studies showed differences in the structure and composition between external and internal enamel $[4,25,26]$. Dentin also showed a different percentage of organic matrix content in spite of approximately normal morphology [4]. These findings indi- 
cate that the mineral content of the hard tissue may also be affected as part of this abnormality, although histological differentiation seems to be relatively well maintained in a dilated odontoma.

In conclusion, the present case is considered an extremely rare case of dilated odontoma with the characteristics as follows: (1) development in the second molar region of the mandible; (2) a completely inverted hard tissue structure without characteristics of the molar tooth; (3) the absence of normally formed second molar tooth in the region. Further analysis of a large collection of samples is needed to clarify the prevalence, features and genesis of a dilated odontoma.

\section{CONFLICT OF INTEREST}

None declare.

\section{REFERENCES}

[1] Alani A, Bishop K. Dens invaginatus. Part 1. classification, prevalence and aetiology. Int Endod J 2008; 41: 1123-36.

[2] Hovland EJ, Block RM. Nonrecognition and subsequent endodontic treatment of dens invaginatus. J Endod 1977; 3: 360-2.

[3] Hülsmann M. Dens invaginatus: aetiology, classification, prevalence, diagnosis, and treatment considerations. Int Endod J 1997; 30: 79-90.

[4] Crincoli V, Di Bisceglie MB, Scivetti M, Favia A, Di Comite M. Dens invaginatus: a qualitative-quantitative analysis. case report of an upper second molar. Ultrastruct Pathol 2010; 34: 7-15.

[5] Chen Y-H, Tseng C-C, Harn W-M. Dens invaginatus: review of formation and morphology with 2 case reports. Oral Surg Oral Med Oral Pathol Oral Radiol Endod 1998; 86: 347-52.

[6] Yeh S-C, Lin Y-T, Lu S-Y. Dens invaginatus in the maxillary lateral incisor. Oral Surg Oral Med Oral Pathol Oral Radiol Endod 1999; 87: 628-31.

[7] Hülsmann M, Hengen G. Severe dens invaginatus malformation. report of two cases. Oral Surg Oral Med Oral Pathol Oral Radiol Endod 1996; 82: 456-8.

[8] Banner H. Bilateral dens in dente in mandibular premolars. Oral Surg Oral Med Oral Pathol 1978; 45: 827-8.

[9] Karaca I, Toller MO. Multiple bilateral dens in dente involving all the premolars. case report. Aust Dent J 1992; 37: 449-52.
[10] Tavano SM, de Sousa SM, Bramante CM. Dens invaginatus in first mandibular premolar. Endod Dent Traumatol 1994; 10: 27-9.

[11] Hartup GR. Dens invaginatus type III in a mandibular premolar. Gen Dent 1997; 45: 584-7.

[12] Canger EM, Kayipma S, Celenk P. Bilateral dens invaginatus in the mandibular premolar region. Ind J Dent Res 2009; 20: 238-40.

[13] Oehlers FA. Dens invaginatus (Dilate composite odontome). I. Variation of the invagination process and associated anterior crown form. Oral Surg Oral Med Oral Pathol 1957; 10: 1204-18.

[14] Yamamoto K, Morimoto Y, Kawakami T, Mishima K, Shiotani H, Sugimura M. A case of dilated odontoma arising in buccal region of 3rd molar tooth of mandible. J Jpn Stomatol Soc 1999; 48: 3959.

[15] Cukovic-Bagic I, Macan D, Dumancic J, Manojlovic S, Hat J. Dilated odontome in the mandibular third molar region. Oral Surg Oral Med Oral Pathol Oral Radiol Endod 2010; 109; e109-13.

[16] Matsumoto Y, Seto K. Histological studies of four cases of dilated odontoma. Oral Med Pathol 1996; 1: 56-9.

[17] Grahnen H, Lindahl B, Omnell K. Dens invaginatus, I: a clinical, roentogenological and genetical study of permanent upper lateral incisors. Odontol Revy 1959; 10: 115-37.

[18] Ekman-Westorg B, Julin P. Multiple anomalies in dental morphology: macrodontia, multituberculism, central cusps, and pulp invaginations; report of a cases. Oral Surg Oral Med Oral Pathol 1974; 38: 217-22.

[19] Kerebel B, Kerebel LM, Daculsi G, Doury J. Dentinogenesis imperfecta with dens in dente. Oral Surg Oral Med Oral Pathol 1983; 55: 279-85.

[20] Pokala P, Acs G. A constellation of dental anomalies in a chromosomal deletion syndrome $(7 \mathrm{q} 32)$ : case report. Pediatr Dent 1994; 16: 306-9.

[21] Bishop K, Alani A. Dens invaginatus. Part 2: clinical, radiographic features and management options. Int Endod J 2008; 41: 1137-54

[22] Sedano HO, Ocampo-Acosta F, Naranjo-Corona R, TorresArellano ME. Multiple dens invaginatus, mulberry molar and conical teeth. Case report and genetic considerations. Med Oral Patol Oral Cir Bucal 2009; 14: e69-72.

[23] de Joubert JJ, Breytenbcah HS, Staz J. Classification of odontomes with report of an invaginated odontome of the complex type. J Dent Assoc S Afr 1981; 36: 823-7.

[24] Stavrou E, Tosios KI, Stavrou IE. Globular radiopacity around the apex of an impacted maxillary third molar. Oral Surg Oral Med Oral Pathol Oral Radiol Endod 2007; 103: 594-8.

[25] Eden EK, Koca H, Sen BH. Dens invaginatus in a primary molar: report of case. ASDC J Dent Child 2002; 69: 49-53.

[26] Bloch-Zupan A, Cousandier L, Hemmerle J. Dens in dente: aspects ultrastructuraux. J d'odnoto-stomatol Pediatr 1997; 7: 47-54.

Received: June 30, 2011

(C) Matsusue et al.; Licensee Bentham Open.

This is an open access article licensed under the terms of the Creative Commons Attribution Non-Commercial License (http://creativecommons.org/licenses/by-nc/3.0/) which permits unrestricted, non-commercial use, distribution and reproduction in any medium, provided the work is properly cited. 